\title{
REFLECTION PHOTOELASTIC AND FINITE ELEMENT RESIDUAL STRESS ANALYSIS OF A TORPEDO POT FOR CAST IRON
}

\author{
Rusu-Casandra Aurelia Liliana ${ }^{\mathrm{a}}$, Baciu Florin ${ }^{\mathrm{a}}$, Iliescu Nicolae ${ }^{\mathrm{a}}$ \\ ${ }^{a}$ Politehnica University of Bucharest, Splaiul Independentei no 313, Bucharest, Sector 6, 060042, Romania
}

\begin{abstract}
Residual stresses in a structural material or component are caused mainly by manufacturing processes. Their effects are often detrimental, as these stresses contribute to fatigue and other structural failures. Therefore for the improvement of the design of a prototype of a torpedo pot, an experimental investigation using "blind-hole drilling" method with photoelastic coatings was employed in order to verify the residual stresses in the weldings of the structure. Due to difficulties encountered during loading and unloading of the pot with the transported liquid cast iron, i.e. high variations of temperatures that occur and lead to measurement errors, the reflection photoelastic measurements were performed on a model. The results obtained were compared with those from a thermal-elastic-plastic finite element analysis of the model employed. The study was necessary in order to estimate the magnitude of the welding residual stresses and to characterize the effects of welding conditions on their values. The information provided was useful for changing the design and fabrication parameters of the iron pot.
\end{abstract}

Keyword: residual stress; photoelastic coatings; blind -hole drilling method; reflection polariscope; torpedo pot; FEM
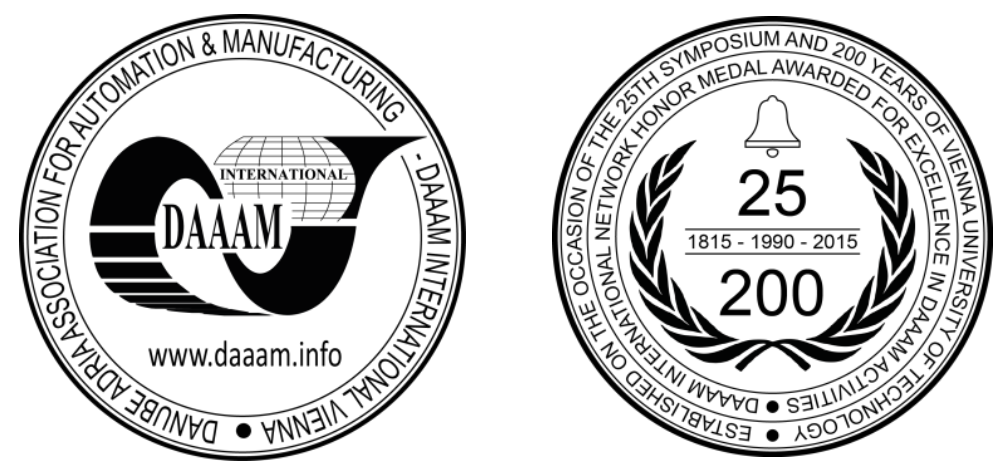

This Publication has to be referred as: Rusu-Casandra, A[urelia] L[iliana]; Baciu, F[lorin] \& Iliescu, N[icolae] (2016). Reflection Photoelastic and Finite Element Residual Stress Analysis of a Torpedo Pot for Cast Iron, Proceedings of the 26th DAAAM International Symposium, pp.0320-0326, B. Katalinic (Ed.), Published by DAAAM International, ISBN 978-3-902734-07-5, ISSN 1726-9679, Vienna, Austria

DOI:10.2507/26th.daaam.proceedings.043 


\section{Introduction}

Research during the past decades increased considerably the knowledge in the field of residual stress analysis. This state of stress may represent one of the most important parameters that influence the performance and structural integrity of an engineering component and its services behavior.

Residual stresses are produced by processes that change the shape of the solid causing nonuniform plastic deformation in the solid (rolling, forming operations), by processes that produce high thermal gradients in the solid (welding, casting), or induce localized phase changes (martensitic hardening) [1].

There are different types of residual stresses, according to the volume size at which they manifest themselves:

- macro residual stresses (stresses of the first order) which are nearly homogenous over macroscopic areas of the material and are primarily the result of various manufacturing processing

- micro residual stresses (stresses of the second order) that exist directly in the crystalline grain and result from changes occurring at the atomic level [2].

In engineering practice, the macro residual stresses are of interest because these stresses influence service properties. The micro residual stresses are of more interest in the materials science.

Most methods for determining residual stresses are developed for the evaluation of macro stresses and the approaches for the analysis of strain - stress state use the models of continuum mechanics. The effectiveness of the chosen method is decided by the type of residual stresses, the material properties, the stress distribution and the geometry of the structure.

Considerable interest is given to the effect of the residual stresses on the behavior of joined components. One of the main assembly methods widely used in industry is welding technology. Experimental, analytical and computational methods are used to analyse the influence of residual stresses on the welded structure, such as: influence on local yield strength of components, on fatigue strength, on elastic stability, on formation of cracks, on increasing the risk of brittle fracture, etc [3, 4].

This paper presents an experimental investigation of the welding residual stresses in a torpedo pot used for the transportation of the liquid cast iron [5]. Due to the high variation of temperature that occur during the loading and unloading of the pot, the macro residual stresses were determined on a model of the prototype, using the photoelastic coating method in combination with the drilling of a circular hole. The results were compared with those obtained from a thermal-elastic-plastic finite element analysis of the model.

\section{Experimental investigation}

The photoelastic coating method is one of the most reliable way to analyse strain fields on the structure surface $[6,7]$. Birefringent coatings are bonded to the surface of the component with a special reflective cement and when the structure is loaded, the surface strains are transmitted to the coating and produce a fringe pattern which is recorded and analysed by means of a reflection polariscope. This method combined with the circular drilling technique is pursued to study residual stresses. The latter involves machining a shallow hole in the component to a depth approximately equal to the hole diameter. The principle is that removal of stressed material results in the redistribution of the stresses in the surrounding region, causing the local strains on the surface to change correspondingly [ 8, 9].

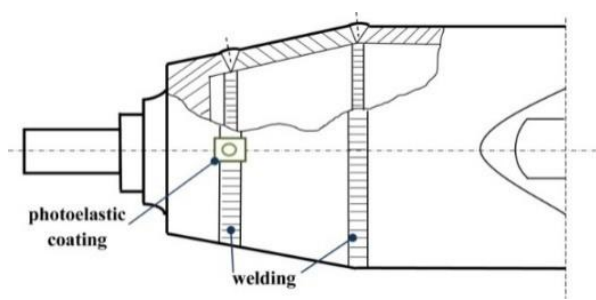

Fig. 1. Experimental investigation area of the weld seam

Experimental measurements were done on the model of a torpedo pot for transporting cast iron. Residual stresses were measured in points situated on the weld seam that joins the steel rolled plates of one of the tapered coatings of the pot (Fig.1).

A photoelastic coating was applied on the investigated area, i.e. a square with dimensions $35 \mathrm{~mm}$, using a corresponding adhesive. Coating was manufactured by VISHAY, type PS-1 with following characteristics: thickness $\mathrm{t}=2.1 \mathrm{~mm}$, fringe value of coating $\mathrm{f}=915 \mu \mathrm{m} / \mathrm{m}$ per fringe, strain optical coefficient of coating $\mathrm{K}=0.15$. The fringe value of coating has the expression $\mathrm{f}=\lambda / 2 \mathrm{tK}$, where $\lambda=576 \mathrm{~nm}$ is wavelength in white light. After hardening of the adhesive, a hole of diameter $2 R_{0}=3 \mathrm{~mm}$ and $4 \mathrm{~mm}$ depth was drilled in the center of the coating. By removing the stressed material, around the hole the material readjusts its stresses to attain equilibrium. With a reflection polariscope 
(Fig.2a and Fig.2b) a field of photoelastic fringes formed around the hole has been observed and the directions of principal stresses were identified.

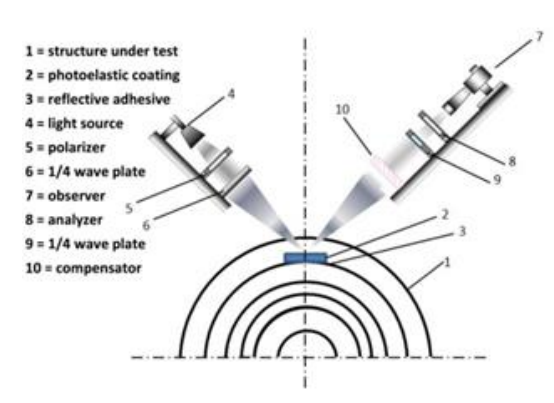

Fig.2a Schematic representation of reflection polariscope

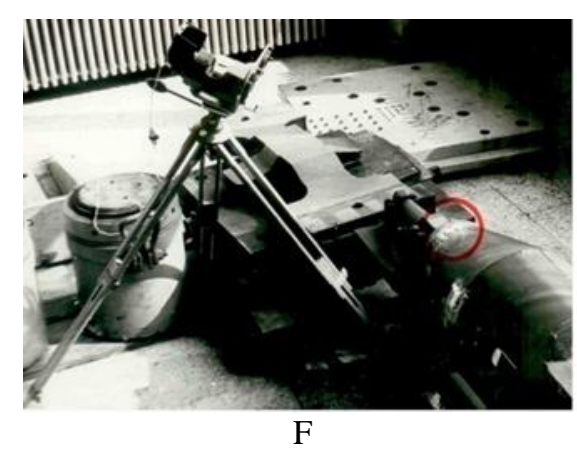

ig.2b Set-up for experimental measurements

The directions were indicated by the axes of symmetry of the photoelastic field: the axis with the lowest fringe order indicates the direction of the principal stress $\sigma_{1}$, while the perpendicular on this direction indicates the direction of principal stress $\sigma_{2}$ (Fig. 3a).

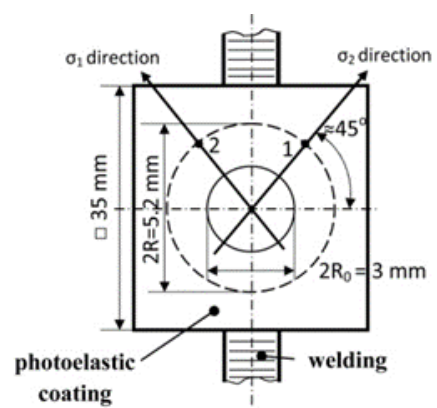

Fig.3a. Directions of principal stresses

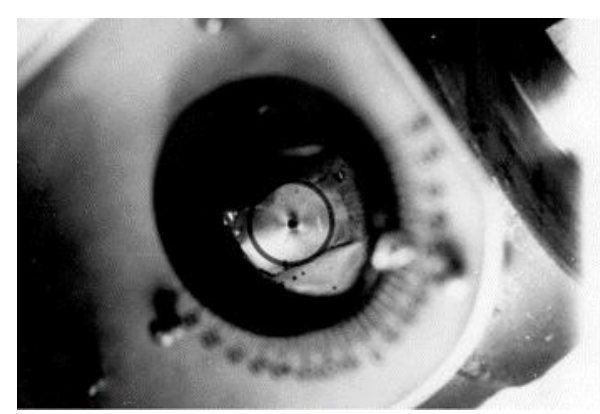

Fig.3b. Fringe pattern around the hole

Using a Babinet compensator (Fig.3b), the fractional values of fringe order $\mathrm{N}$ were determined in two points 1 and 2 on these directions at the distance $\mathrm{R}=\sqrt{3} R_{0}=2.6 \mathrm{~mm}$ from the center of the hole: $\mathrm{N}_{1}=0.45$ fringes and $\mathrm{N}_{2}=$ 0.125 fringes. The fringe orders observed in the photoelastic coating are proportional to the difference between the principal strains in the coating (and in the surface of the model of the pot). This linear relationship is expressed as follows [10]:

$$
\varepsilon_{\mathrm{r}}-\varepsilon_{\theta}=\mathrm{Nf}
$$

here $\varepsilon_{\mathrm{r}}$ and $\varepsilon_{\theta}$ are the radial and tangential normal strains respectively relieved at the measurement point.

The photoelastic measurements were performed on the directions of principal stresses $\sigma_{1}$ and $\sigma_{2}$, in two points situated on a circle around the hole. The necessary relationships to calculate the values of the principal stresses in these points in the proximity of the hole are determined as follows [11] :

It is known in the theory of elasticity that if over a plane state of stress is superposed a second state of stress occurring from a uniform distribution of loads on the contour of a hole, the resulting state of stress is identical to the one formed around a hole, free on contour, placed in a plate loaded on two directions.

In the case of a thin plate subjected to uniform residual stress, after a small hole has been drilled through it (Fig.4), the stresses $\sigma_{r}$ and $\sigma_{\theta}$ (along the radius and tangent respectively) at a point $\mathrm{P}(\mathrm{R}, \theta)$ can be expressed in polar coordinates in function of the principal stresses $\sigma_{1}$ and $\sigma_{2}$, and in function of the geometric relations between the point and the hole and between the point and the principal axes:

$$
\begin{aligned}
& \sigma_{\mathrm{r}}=\frac{\sigma_{1}+\sigma_{2}}{2}\left(1-\frac{1}{\mathrm{r}^{2}}\right)+\frac{\sigma_{1}-\sigma_{2}}{2}\left(1-4 \frac{1}{\mathrm{r}^{2}}+3 \frac{1}{\mathrm{r}^{4}}\right) \cos 2 \theta \\
& \sigma_{\theta}=\frac{\sigma_{1}+\sigma_{2}}{2}\left(1+\frac{1}{\mathrm{r}^{2}}\right)-\frac{\sigma_{1}-\sigma_{2}}{2}\left(1+3 \frac{1}{\mathrm{r}^{4}}\right) \cos 2 \theta
\end{aligned}
$$

where $r=R / R_{0}\left(R \geq R_{0}\right), \mathrm{R}_{0}$ is the radius and $\mathrm{R}$ is an arbitrary radius from hole center. 


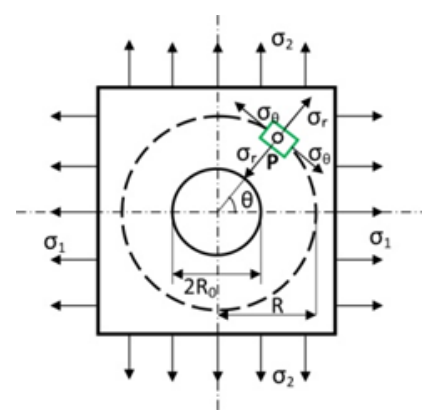

Fig.4. Stresses in a plate with a hole

In the case of the plate without holes, equations (2) become:

$$
\begin{aligned}
& \sigma_{\mathrm{r}}^{\prime}=\frac{\sigma_{1}+\sigma_{2}}{2}+\frac{\sigma_{1}-\sigma_{2}}{2} \cos 2 \theta \\
& \sigma_{\theta}^{\prime}=\frac{\sigma_{1}+\sigma_{2}}{2}-\frac{\sigma_{1}-\sigma_{2}}{2} \cos 2 \theta
\end{aligned}
$$

Subtracting stresses (3) from final stresses after drilling (2) one can find the stress relieved at point P:

$$
\begin{aligned}
& \Delta \sigma_{\mathrm{r}}=\sigma_{\mathrm{r}}-\sigma_{\mathrm{r}}^{\prime}=-\frac{\sigma_{1}+\sigma_{2}}{2} \cdot \frac{1}{\mathrm{r}^{2}}+\frac{\sigma_{1}-\sigma_{2}}{2}\left(3 \frac{1}{\mathrm{r}^{4}}-4 \frac{1}{\mathrm{r}^{2}}\right) \cos 2 \theta \\
& \Delta \sigma_{\theta}=\sigma_{\theta}-\sigma_{\theta}^{\prime}=\frac{\sigma_{1}+\sigma_{2}}{2} \cdot \frac{1}{\mathrm{r}^{2}}-\frac{\sigma_{1}-\sigma_{2}}{2} \cdot 3 \cdot \frac{1}{\mathrm{r}^{4}} \cdot \cos 2 \theta
\end{aligned}
$$

To these stresses correspond, in point $\mathrm{P}$, the relieved strains:

$\varepsilon_{\mathrm{r}}=\frac{1}{\mathrm{E}}\left(\Delta \sigma_{\mathrm{r}}-v \Delta \sigma_{\theta}\right)$

$\varepsilon_{\theta}=\frac{1}{\mathrm{E}}\left(\Delta \sigma_{\theta}-v \Delta \sigma_{\mathrm{r}}\right)$

where E is Young's modulus and $v$ is Poisson's ratio. The expression of their differences is

$\varepsilon_{\mathrm{r}}-\varepsilon_{\theta}=\frac{1+v}{\mathrm{E}}\left(\Delta \sigma_{\mathrm{r}}-\Delta \sigma_{\theta}\right)$

Substitution of equations (4) in equation (6) for $\theta=0^{\circ}$ and $\theta=90^{\circ}$ yields:

$$
\begin{aligned}
& \left(\varepsilon_{\mathrm{r}}-\varepsilon_{\theta}\right)_{\theta=0^{\circ}}=-\sigma_{1} \frac{1+v}{\mathrm{E}}\left(\frac{3}{\mathrm{r}^{2}}-\frac{3}{\mathrm{r}^{4}}\right)-\sigma_{2} \frac{1+v}{\mathrm{E}}\left(\frac{3}{\mathrm{r}^{4}}-\frac{1}{\mathrm{r}^{2}}\right) \\
& \left(\varepsilon_{r}-\varepsilon_{\theta}\right)_{\theta=90^{\circ}}=-\sigma_{1} \frac{1+v}{E}\left(\frac{3}{r^{4}}-\frac{1}{r^{2}}\right)-\sigma_{2} \frac{1+v}{E}\left(\frac{3}{r^{2}}-\frac{3}{r^{4}}\right)
\end{aligned}
$$

If the stresses $\sigma_{r}$ and $\sigma_{\theta}$ are determined on a circle of radius $R=\sqrt{3} R_{0}$ (for $\theta=0^{\circ}$ and $\theta=90^{\circ}$ ) equations (7) become:

$$
\varepsilon_{\mathrm{r}}-\varepsilon_{\theta}=\frac{2}{3} \cdot \frac{1+v}{\mathrm{E}} \sigma
$$

where $\sigma$ might be $\sigma_{1}$ or $\sigma_{2}$ as $\theta=0^{\circ}$ or $\theta=90^{\circ}$ respectively.

Combination of equation (1) with equation (8) yields:

$\sigma=\frac{3 \mathrm{E}}{2(1+v)} \mathrm{Nf}$

Using this relationship and taking into account that $\mathrm{N}_{1}$ and $\mathrm{N}_{2}$ were measured on the directions of principal residual stresses $\sigma_{1}$ and $\sigma_{2}$ in two points 1 and 2 (Fig. $3 \mathrm{a}$ ) situated on a circle with the radius $\mathrm{R}=\sqrt{3} R_{0}=2.6 \mathrm{~mm}$, the values of $\sigma_{1}$ and $\sigma_{2}$ were $\sigma_{1}=99.77 \mathrm{MPa}$ and $\sigma_{2}=27.7 \mathrm{MPa}$ (with $\mathrm{E}=2.1 \times 10^{5} \mathrm{MPa}$ and $v=0.3$ ). 


\section{Finite element analysis}

A finite element analysis was performed using SolidWorks software [12]. The finite element mesh for the model of the prototype of the torpedo pot with the welding joining the steel rolled plates of the central cylinder shell and the two tapered coating ends (Fig.5) was generated using nine-noded tetragonal nonlinear elements and consisted of 714,410 elements and $1,397,385$ nodes.

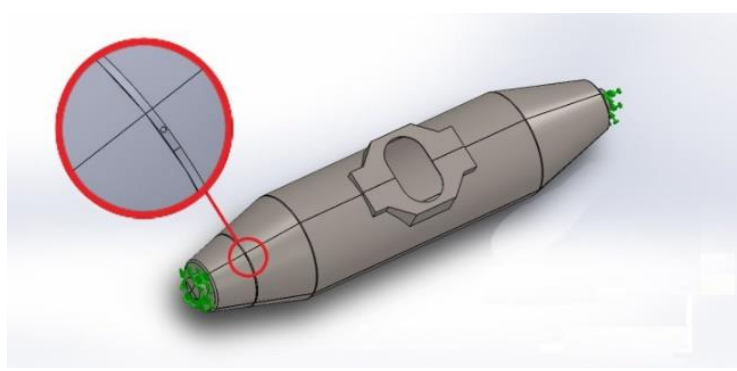

Fig. 5. The model of the torpedo pot

First a thermal elastic-plastic FE analysis was done, the model being heated at $800 \mathrm{o}$ C. The thermal field and von Mises stress distribution in the same area that was investigated experimentally are shown in Fig.6 and Fig.7 respectively.
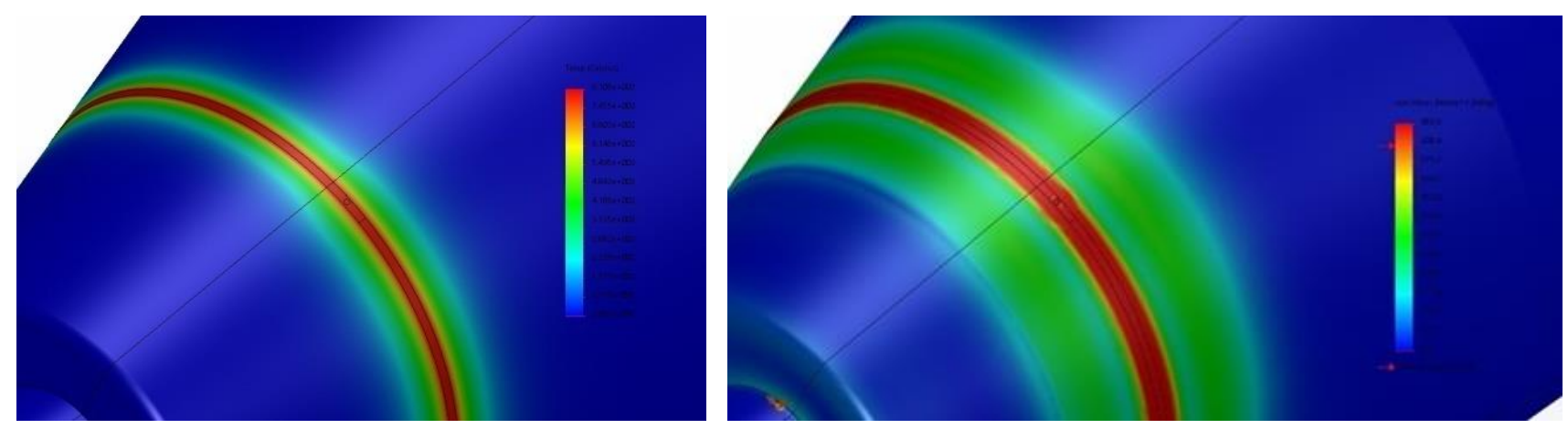

Fig. 6. Distribution of thermal field of welding at 800 o C

Fig.7 Distribution of von Mises stresses at $800 \mathrm{o} C$

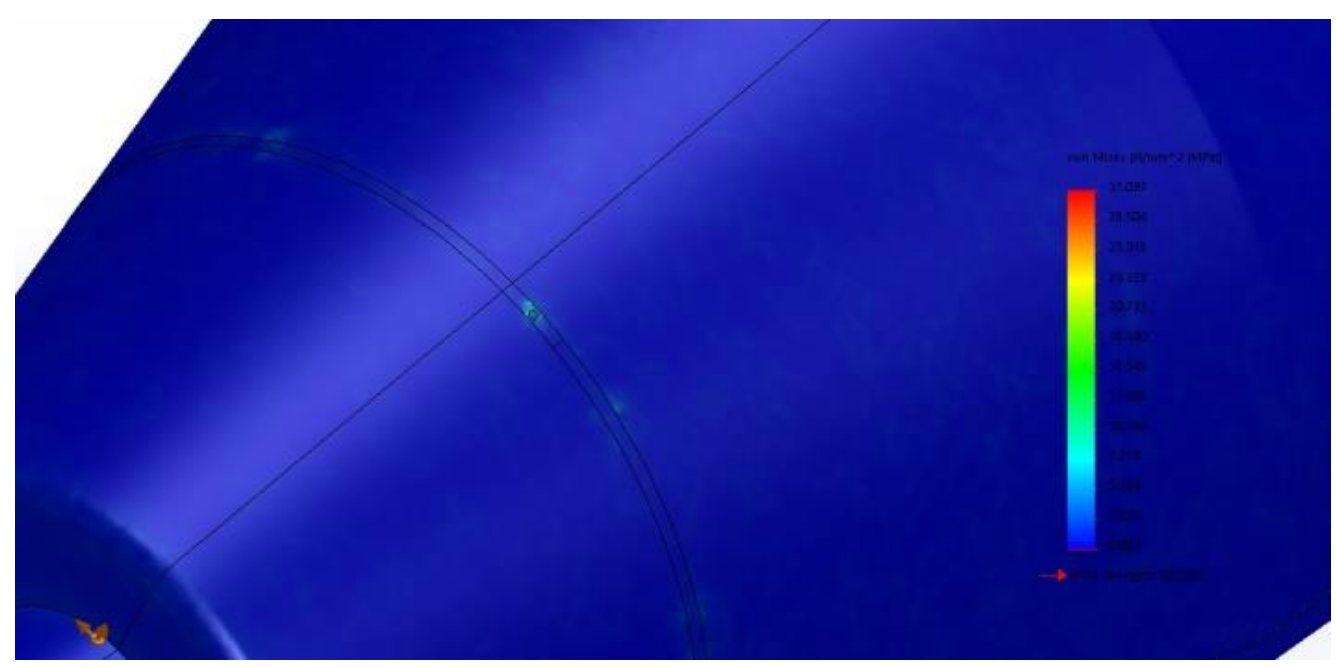

Fig. 8. Values of von Mises stresses at 25o C

A sample has been cut from the weld seam at $25 \mathrm{o} C$ in the region experimentally studied and the hole of $3 \mathrm{~mm}$ diameter and $4 \mathrm{~mm}$ depth drilled in the welding was simulated. A more refined mesh was chosen for the sample in order to get more accurate results (Fig.9). 


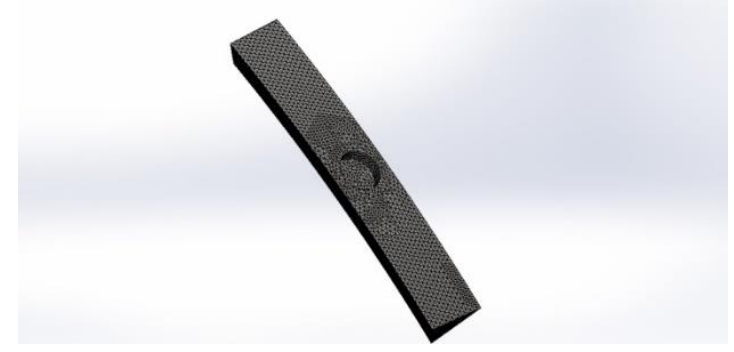

Fig. 9 Mesh of the sample

The distributions of principal strains $\varepsilon_{1}$ and $\varepsilon_{2}$ are shown in Fig.10a and Fig.10b respectively.

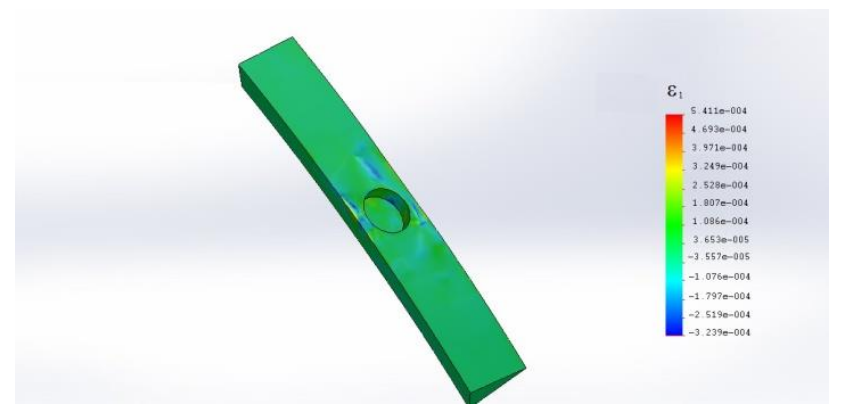

Fig.10a Principal strains $\varepsilon_{1}$ distribution around the hole

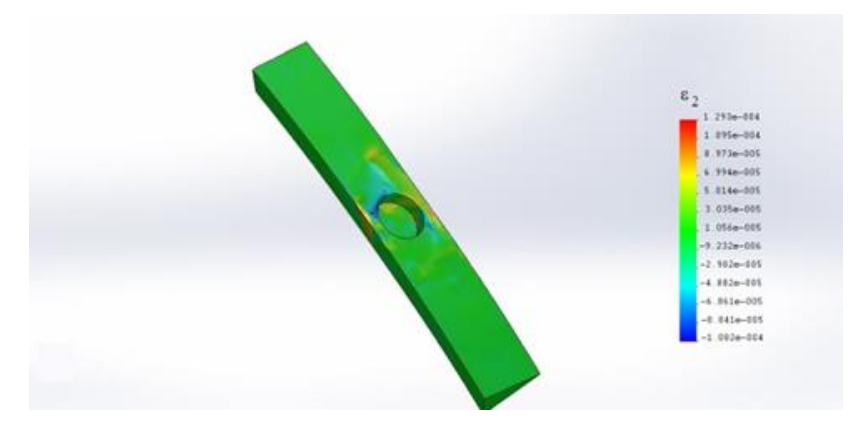

Fig.10b Principal strains $\varepsilon_{2}$ distribution around the hole

Figure 11 presents von Mises stresses.

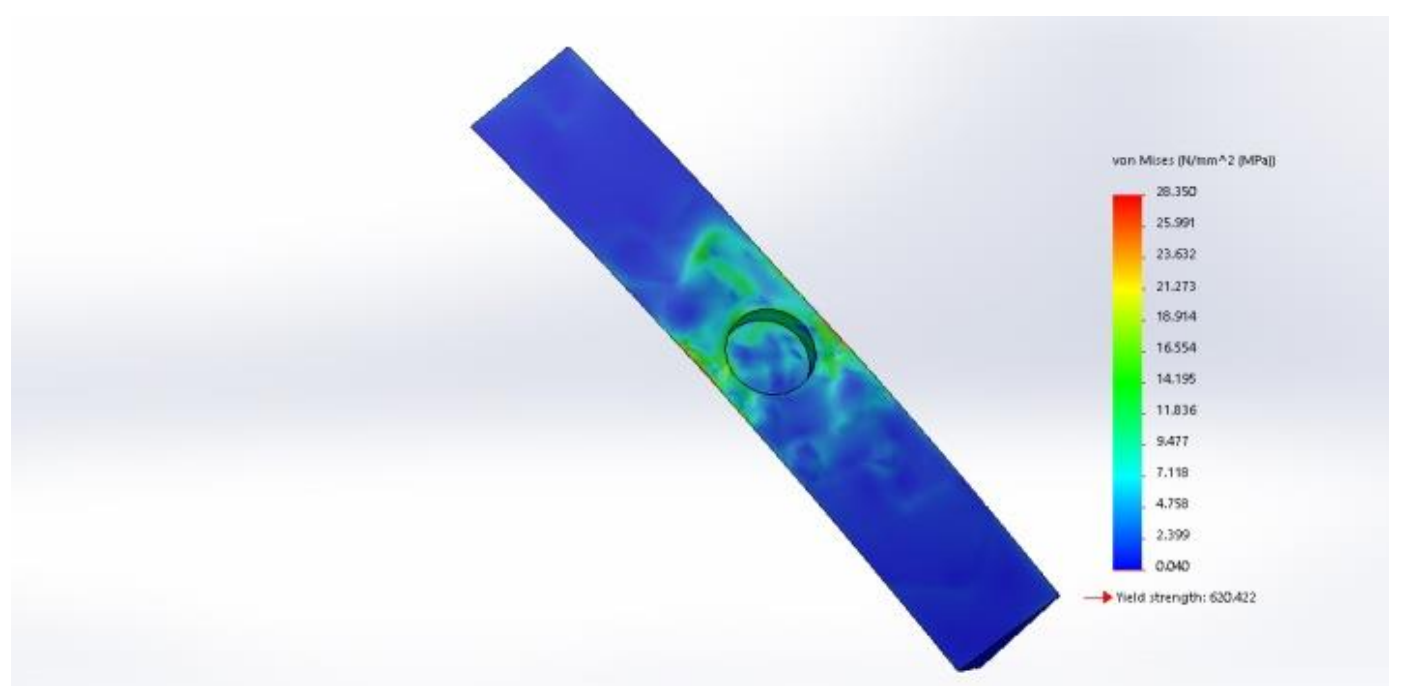

Fig. 11. von Mises stresses distribution around the hole.

\section{Conclusions}

In this paper, reflection photoelastic measurements and thermal-elastic-plastic finite element analysis are presented, in order to estimate the magnitude of macro residual stresses in a welded joint of a prototype of a torpedo pot used for transportation of liquid cast iron. According to experimental measurements and numerical simulation results, the following conclusions can be drawn:

- The modelling results showed reasonable agreement with the experiments. Thus, after the determination of principal strains $\varepsilon_{1}$ and $\varepsilon_{2}$ distributions (Fig.10a and Fig.10b), the values calculated for principal residual stresses in points situated in approximately the same area experimentally investigated were $\sigma_{1}=92.7 \mathrm{MPa}$ and $\sigma_{2}=26.03 \mathrm{MPa}$. It can be remarked that the error between the calculated and measured results is just about $6 \%$. The differences can be explained considering the difficulties of modelling the different behaviours of the 
weld and of the parent metal respectively during the process of welding, and also due to the fact that the points in which the stresses were measured were not identical to the ones in which FE results were obtained.

- The maximum values of von Mises stresses in the welded joint when the model was heated at $800^{\circ} \mathrm{C}(\mathrm{Fig} .7)$ and then cooled at $25^{\circ} \mathrm{C}$ (Fig.8) were $685.48 \mathrm{MPa}$ and $31.1 \mathrm{MPa}$ respectively. After a hole was drilled in the sample cut from the weld seam, due to strain-stress relief, the maximum value of von Mises stresses in the area around the hole is lower, i.e. $28.35 \mathrm{MPa}$ (Fig.11).

- The useful information provided by this study, i.e. the knowledge of the stress field in the weld core is important to understanding the impact of macro residual stresses on the performance and structural integrity of the torpedo pot. It is better to achieve this goal during an early stage of design and fabrication.

- As future work, to reduce the values of residual stresses in the weld joints of the prototype to acceptable levels, adequate design measures must be considered to optimize its structural shape

\section{References}

[1] C. Ruud, Measurement of Residual Stresses, in G. Totten, M. Howes, T. Inoue (Eds.), Handbook of Residual Stresses and Deformation of Steel, ASM International, Materials Park, Ohio, ISBN 0-87170-729-2, 2002, pp. 99117.

[2] I.A. Razumovsky, M.V. Medvedev, and A.V. Fomin, Methods for Determination ofInhomogeneous Residual Stress Fields, in G. Totten, M. Howes, T. Inoue (Eds.), Handbook of Residual Stresses and Deformation of Steel, ASM International, Materials Park, Ohio, ISBN 0-87170-729-2, 2002, pp.125-138.

[3] P. Ramakrishnan, Residual Stresses in Powder-Metal Processing, in G. Totten, M. Howes, T. Inoue (Eds.), Handbook of Residual Stresses and Deformation of Steel, ASM International, Materials Park, Ohio, ISBN 087170-729-2, 2002, pp.391-396.

[4] H. Long, D. Gery, A. Carlier, P.G. Maropoulos, Prediction of welding distortion in butt joint of thin plates, Materials \& Design, Volume 30, Issue 10, Elsevier Ltd., 2009, pp. 4126-4135.

[5] A. Rusu-Casandra, F. Baciu, N. Iliescu, C. Atanasiu, Stresses and strains in a torpedo pot for cast iron, Annals of DAAAM for 2012 \& Proceedings of the 23rd International DAAAM Symposium, Vol. 23, No. 1, ISSN 23041382, ISBN 978-3-901509-91-9, Viena, Austria, 2012.

[6] J. A. Sue, G. S. Schajer, Stress Determination in Coatings, in G. Totten, M. Howes, T. Inoue (Eds.), Handbook of Residual Stresses and Deformation of Steel, ASM International, Materials Park, Ohio, ISBN 0-87170-729-2, 2002, pp.118-124.

[7] G.S. Schajer (Editor), Practical Residual Stress Measurement Methods, John Wiley \& Sons, ISBN 978-1-11834237-4, Chichester, UK, 2013.

[8] Measurement of Residual Stresses by the Hole-Drilling Strain Gage Method, Technical Note TN-503, VISHAY PRECISION GROUP, www.micro-measurements.com, 2010.

[9] X. Huang, Z. Liu, H. Xie, Recent progress in residual stress measurement techniques, Acta Mechanica Solida Sinica, Vol. 26, No. 6, December 2013, ISSN 0894-9166, AMSS Press, Wuhan, China, 2013, pp. 570-583.

[10] J.W. Dally, W.F. Riley, Experimental stress analysis, McGraw-Hill, ISBN 978-0070152045, New York, USA, 1991.

[11] M. L. Kachanov, B. Shafiro, I. Tsukrov, Handbook of Elasticity Solutions,ISBN 970-90-481-6362-5, Springer Science \& Business Media, 2003.

[12] *** (2015) Solidworks user manual, Dassault Systèmes SolidWorks Corp, Concord, MA, USA. 